\title{
Effect of organic amendments and solarisation on Fusarium wilt in susceptible banana plantlets, transplanted into naturally infested soil
}

\author{
N. Nasir ${ }^{\mathrm{A}}$, P. A. Pittaway ${ }^{\mathrm{B}}$, and K. G. Pegg ${ }^{\mathrm{C}}$ \\ ${ }^{\text {A }}$ School of Agronomy and Horticulture, University of Queensland, Gatton Campus, Qld 4343, Australia; \\ present address: Solok Research Institute for Fruits, Department of Agriculture, \\ PO Box 5, West Sumatra, Indonesia. \\ ${ }^{\text {B } C o r r e s p o n d i n g ~ a u t h o r ; ~ C h r y s a l i s ~ L a n d s c a p e ~ C o n s u l t a n t s, ~} 31$ Douglas McInnes Drive, Laidley, Qld 4341, \\ Australia; email: grubb@hypermax.net.au \\ ${ }^{\mathrm{C}}$ Queensland Horticulture Institute, Queensland Department of Primary Industries, Meiers Rd, Indooroopilly, \\ Qld 4068, Australia.
}

\begin{abstract}
Despite extensive research since pathogenicity was first established in 1919, no cultural or chemical control strategy has proven effective against Fusarium wilt of bananas. The efficacy of cultural control is attributed to the suppression of pathogen activity. Yet, amending naturally infested soil with aged chicken manure has been shown to enhance disease severity, without any change in the activity of the pathogen Fusarium oxysporum $\mathrm{f}$. sp. cubense (Foc) in the soil. In this study, the effect of amending soil with composted sawdust, and of solarising soil, was compared with the effect of amending soil with chicken manure. Bioassays comparing the activity of Foc in the soil with the extent of invasion of banana pseudostem tissue by Foc were used to investigate why strategies targetting pathogen survival have not proven successful in controlling this disease.

The enhancement of $F o c$ invasion of the banana plantlets was reproduced with the addition of chicken manure to the naturally infested soil. However, changes in the activity of $F o c$ in the soil were not associated with changes in the frequency of invasion of the plantlets. Invasion of banana pseudostems in the sawdust and solarisation treatments was not significantly different from invasion in the respective control treatments, despite a reduction in the activity of $F o c$ in the sawdust-amended soil and an enhancement in the solarised soil. Moreover, the increase in $F o c$ activity in the solarised soil recorded during the bioassays occurred despite the effectiveness of solarisation in reducing the survival of Foc in pre-colonised banana root tips buried in the soil. Changes in the frequency of invasion were associated with changes in the availability of mineral nitrogen, particularly ammonium N. These results suggest that the physiological response of banana cultivars to ammonium $\mathrm{N}$ may be associated with their susceptibility to Fusarium wilt. Accordingly, cultural strategies for controlling Panama disease will only be effective if they enhance the ability of the host to resist invasion.
\end{abstract}

Additional keywords: bioassay, Panama disease, nitrogen.

\section{Introduction}

The wilt disease of bananas, later known as Panama disease, was first described in Queensland, Australia, by Dr Joseph Bancroft in 1874 (Pegg et al. 1996). Bancroft advised growers to select planting material from plants free of disease, a strategy that remains the cornerstone of Panama disease management in Australia today. The pathogenicity of the causal agent Fusarium oxysporum Schlecht. f. sp. cubense (E. F. Smith) Snyd. \& Hans. (Foc) was first demonstrated in 1919. Despite a concerted research effort since that time, no cultural or chemical strategy has provided long-term disease control in any country where bananas are grown. However, cultural control techniques have proven successful with wilt diseases caused by other species of Fusarium, and by other strains of Fusarium oxysporum ( Fo).

Several cultural control strategies have been shown to reduce the survival of Fusarium wilt pathogens in soil and in plant debris. Chemical extractives present in composted sawdust were found to suppress the activity of Fusarium species in amended soil, by stimulating the activity of antagonistic microbes (Kai et al. 1990). Similarly, the stimulation of populations of antagonistic microbes in soil amended with various organic composts was also shown to reduce the survival of Fusarium wilt pathogens (Hoitink and Fahy 1986). Studies using artificial inocula of Fo f. sp. elaeidis showed that farmyard manure consistently reduced 
the survival of chlamydospores in amended soil (Oritsejafor and Adeniji 1990). Solarisation was also shown to reduce the survival of Fo in soil (DeVay and Katan 1991). However, despite successfully reducing the population of $F O$ in solarised soil, Porter and Merriman (1985) were unable to reduce the severity of wilt disease in susceptible carnation and watermelon hosts. Similarly, Amir and Allabouvette (1993) and Abawi and Lorbeer (1971) found no correlation between the inoculum potential of pathogenic strains of $F O$ and wilt disease severity in infested soils.

Lack of an association between the inoculum potential of a pathogen and disease severity suggests that factors other than pathogen activity may determine the outcome of these host-pathogen interactions. Fo is known to invade both resistant and susceptible host cultivars (Beckman et al. 1962; Baayen and Elgersma 1985), implying that resistance depends on the ability of the host to restrict invasion after infection. The pathogen must be locally present to infect, but an increase in the activity of the pathogen is not a prerequisite for increasing disease severity. If this is the case, then cultural control strategies will only be effective if they enhance the ability of the host to resist invasion. Conversely, management practices that reduce the ability of the host to resist invasion will increase disease severity independently of any changes in pathogen activity.

The hypothesis being tested in this study is that infection by the pathogen is required for Panama disease, but that disease severity does not conform to a dose-response model. In a previous study, amending soil naturally infested with Foc with chicken manure was found to increase wilt disease severity in susceptible bananas in the absence of any change in the activity of the pathogen population in the soil (Pittaway et al. 1999). In this study the chicken manure effect was used as a reference, to confirm the sensitivity of the activity and invasion bioassays in monitoring changes in pathogen activity and disease incidence, respectively.

The activity of Foc in naturally infested soil was assayed by isolating Foc colonies from buried, excised banana root tips recovered from the soil treatments (pathogen activity). The frequency of Foc invasion of a susceptible banana cultivar was assayed by recovering transplanted banana plantlets after 4 weeks of growth in the different soil treatments and isolating Foc colonies from the pseudostem tissue (disease incidence). The results of the activity and invasion bioassays for the different cultural treatments were compared, to provide insights into why strategies targetting pathogen populations in the soil have not proven successful in the control of Fusarium wilt of bananas.

\section{Materials and methods}

\section{Soil and soil treatment preparation}

A soil type naturally infested with Foc race 4 was collected from under cv. Cavendish plants at a breeding trial site at Wamuran $\left(27^{\circ} 3^{\prime} \mathrm{S}\right.$, $\left.152^{\circ} 22^{\prime} \mathrm{E}\right)$ in south-eastern Queensland. Field soil was collected to a depth of $20 \mathrm{~cm}$ from under a canopy of mature banana plants showing wilt symptoms characteristic of Panama disease. The soil was stored in the field state in 55-L plastic bins under ambient temperature conditions. Before use the soils were sieved $\left(1-\mathrm{cm}^{2}\right.$ grid) to remove coarse plant debris and to crumble larger soil aggregates.

Chicken manure was collected at $1 \mathrm{~m}$ depth from a deep litter poultry shed (litter had accumulated over a 6-month period). The soil was amended at a ratio of 9:1 (v:v) field soil and aged chicken manure (Pittaway et al. 1999). Hardwood sawdust (predominantly Eucalyptus maculata and E. crebra) was collected from a local sawmill and composted in a $1-\mathrm{m}^{3}$ retaining box for 16 weeks. Four black, slotted pipes $(10 \mathrm{~cm}$ diameter) were placed through the centre of the pile to improve aeration. Urea was mixed evenly with the sawdust at a rate of $2.5 \mathrm{~kg} / \mathrm{m}^{3}$ to enhance the composting process. The compost was watered weekly for the first 4 weeks, and fortnightly thereafter. The heap was turned manually at each watering. The compost was assayed on a weekly basis for the presence of residual toxic leachates, using the radish germination and seedling radicle elongation phytotoxicity test (Anon. 1989). A commercial peat:perlite:vermiculite mixture $(1: 1: 1 \mathrm{v}: \mathrm{v})$ amended with $2 \mathrm{~g} / \mathrm{L}$ of miniosmocote slow-release fertiliser (Scotts Australia Pty Ltd) was used as a non-toxic reference medium. Ten Petri dishes per treatment and 10 seeds per dish were used for each assay. The compost was considered mature when no evidence of phytotoxicity could be detected (16 weeks). The soil was amended at a ratio of $8: 2$ (v:v) field soil and composted sawdust (Serra-Wittling et al. 1996).

Subsamples of the field soil were solarised for 7 weeks over the summer period, commencing 5 December 1994. Two raised wooden retainers ( 1.25 by $1.0 \mathrm{~m}$ and $0.8 \mathrm{~m}$ deep) were constructed on a concrete pad and were lined with plastic film. A bed of washed sand was placed into each retainer to a depth of $5 \mathrm{~cm}$, prior to filling each with soil. Both soils were watered to field capacity prior to placing plastic film over the surface (Duff and Barnaart 1992). For the solarised treatment, plastic film $0.50 \mu \mathrm{m}$ in thickness was pressed as close to the soil surface as possible. For the control treatment the plastic film was placed $50 \mathrm{~cm}$ above the soil surface, as a rain shelter.

The survival of Foc inocula over the 7 weeks was monitored by burying 100 pre-colonised banana root segments to a depth of $5 \mathrm{~cm}$, into each of the soil retainers. Plantlets of the susceptible cv. Williams were grown in soil-less media for 4-6 months, after which time 2-cm root segments were cut from the first $4 \mathrm{~cm}$ of each root. The root segments were inoculated by inserting sterilised steel quilting pins into one end, and placing the segments onto $1 / 6$ strength potato dextrose agar (PDA) in a radius around an agar wedge culture of Foc VCG 0120 . The plates were incubated for 5 days prior to burial. After the 7-week solarisation period the root segments were recovered, surface-sterilised in $3 \%$ sodium hypochlorite for $15 \mathrm{~s}$, rinsed in sterile water, and blotted dry. Each segment was cut into 5 subsections prior to plating onto 1/6 PDA amended with $0.5 \mathrm{~g} / \mathrm{L}$ of streptomycin, and incubated at $20^{\circ} \mathrm{C}$ under a black light. The volatile odour test (Moore et al. 1991) was used to distinguish between saprophytic and pathogenic strains of Fo. Five mycelial replicates taken from each monoconidial pure culture were tested. Pure cultures of each isolate were then assigned to a Vegetative Compatibility Grouping using the methods of Moore et al. (1993). VCG reference mutants $0120,0124,0125$, and 0129 were tested against each of the pure cultures, testing 6 nit mutants generated per pure culture.

Soil analyses of $\mathrm{NO}_{3}-\mathrm{N}$ and $\mathrm{NH}_{4}-\mathrm{N}$ were taken at the end of each series of experiments, on soil samples extracted with $2 \mathrm{M} \mathrm{KCl}$ (Catchpole and Weier 1980). Total N was estimated by Kjeldahl digestion of ground material $<2 \mathrm{~mm}$ in diameter (Dalal et al. 1984). Three subsamples were analysed for each experimental treatment and control.

Foc activity and invasion bioassays

Amended, unamended, solarised, and unsolarised soil treatments were placed on geotextile (Bidim A12 Geofabrics, Australia) over a 
2-cm-deep bed of washed sand, in plastic trays 45 by $31 \mathrm{~cm}$ and $25 \mathrm{~cm}$ deep. Capillary watering was achieved by maintaining a permanent reservoir of water within the sand, refilling 2 inverted wine bottles per tray as required. Sterile gravel was placed over the surface, to improve capillary rise to the soil surface. Two waterbaths, holding only 3 trays each, were set at $27^{\circ} \mathrm{C}$ and used to incubate the soil trays for the 3 series of experiments. Each experimental series consisted of 3 treatment trays, interspersed with 3 control trays. All trays were equilibrated for a fortnight prior to the commencement of the bioassays.

The activity of FOC in the soil of each of the 3 experiments was assayed by burying 10 root tips excised from the susceptible cv. Williams, to a depth of $5 \mathrm{~cm}$ in each tray. The root segments were buried at the time the banana plantlets were transplanted into each tray, placed in a grid pattern midway between the transplants. Each root tip had a sterile steel quilting pin inserted into one end to aid in the recovery of the segments, which occurred 5 days after burial. After recovery, each segment was washed and surface-sterilised in 3\% sodium hypochlorite for $15 \mathrm{~s}$, prior to cutting into 10 subsections and plating onto $1 / 6$ PDA-streptomycin agar. One pure-cultured isolate per original root tip segment was identified as a race 4 pathogen, using the volatile odour test. The activity of Foc was calculated as the proportion of the 10 buried root segments per tray, colonised by the pathogen.

The extent of invasion of the banana transplants by Foc was assayed by harvesting the plantlets destructively after 4 weeks. Initially, 6-week-old tissue-cultured plantlets of the susceptible cv. Grande Naine were deflasked and grown on in soil-less potting media for a further 4 weeks prior to transplanting. Ten plantlets were transplanted in a grid pattern into each of the 3 treatment and control trays per experimental series. After 4 weeks the plantlets were removed from the soil and washed, and the pseudostem tissue was dissected from each plantlet and surface-sterilised in 3\% sodium hypochlorite for $15 \mathrm{~s}$. After rinsing in sterile water, each pseudostem was cut into 10 segments and plated onto 1/6 PDA-streptomycin agar. One Foc isolate recovered from each invaded pseudostem was identified using the volatile odour test. The invasiveness of Foc (invasion) was calculated as the frequency of the total of 10 banana plantlets per tray, from which Foc was recovered from the pseudostem tissue.

\section{Statistical analysis of the data}

Data for the activity and invasion assays for each treatment and control series were entered binomially (zero for absence, one for presence of Foc) into a log-linear statistical model (Genmod procedure of the SAS computer package version 6.10), specifying the logit link function. An analysis of deviance approximated by the chi-square distribution $\left(\chi^{2}\right)$ was used to test for effects attributable to the 2 waterbaths and the 3 trays used per treatment, and the soil treatment. Changes in the activity of Foc in the soil associated with the 3 treatments were compared with the changes in pseudostem invasion using a proportional odds model. Results were presented as the log of the odds ratio, plus and minus the $\log$ of the $95 \%$ confidence interval estimates, using the unamended soil pairs as the zero base-line. Comparison across the 3 series of experiments is justified on the basis that any temporal differences in soil receptivity or plant physiology should equally affect both the treatment and control pairs, effectively cancelling out.

\section{Results}

\section{Effect of organic amendments and solarisation on the activity of Foc}

The activity of Foc in the unamended control pairs of each of the 3 experimental series was uniformly high, ranging from 80 to $88.7 \%$ (Table 1). Throughout the experiments, Foc activity was not affected by differences between waterbaths or between the 3 trays used for each series. Treatment effects were only significant for the composted sawdust amendment $\left(\chi^{2}=6.522, P=0.011\right)$ and for the solarised soil $\left(\chi^{2}=8.764\right.$, $P=0.003)$. Amending the soil with chicken manure had no significant effect on the activity of Foc $\left(\chi^{2}=2.394\right.$, $P=0.122$ ). Accordingly, there was evidence of pathogen suppression associated with the sawdust amendment, with activity reduced from $80 \%$ in the control to $72 \%$ in the amended trays. Unexpectedly, pathogen activity was enhanced when the solarised soil was used in the bioassay ( $89 \%$ in the unsolarised control, $95 \%$ in the solarised), despite evidence of pathogen population reduction during solarisation.

Of the 97 root tips recovered from the unsolarised soil, Foc was recovered from 95 (97.9\% recovery). In contrast, in the solarised soil, of the 94 root tips recovered, Foc was recovered from only $3(3.2 \%$ recovery). Saprophytic overgrowth was evident in the agar of only 2 of the total of

Table 1. Frequency of plantlets showing disease symptoms at 4 weeks after transplanting, frequency of buried root tip segments from which Foc was recovered (activity), and frequency of banana plantlet pseudostems from which $F o c$ was recovered (invasion)

Soil naturally infested with Foc race 4 was amended (v : v) with either $10 \%$ chicken manure or $20 \%$ composted sawdust, or was solarised for 7 weeks. An unamended control was compared with each soil treatment. The susceptible cv. Grande Naine was transplanted into the soil at 4 weeks post-deflasking (total 10 per treatment). The analysis of deviance was used to compare the results of each treatment and control pair for Foc activity and invasion (total 30 per treatment)

\begin{tabular}{lccc}
\hline Soil treatment & $\begin{array}{c}\text { Plantlets with } \\
\text { disease } \\
\text { symptoms (\%) }\end{array}$ & $\begin{array}{c}\text { Buried root tips from } \\
\text { which Foc was } \\
\text { recovered (\%) }\end{array}$ & $\begin{array}{c}\text { Plantlet pseudostems } \\
\text { from which Foc was } \\
\text { recovered }(\%)\end{array}$ \\
\hline Amended with 10\% chicken manure & 100 & 95.3 n.s. & $78.7 * * *$ \\
Unamended control & 16.7 & 86.7 & 24.0 \\
Amended with 20\% composted sawdust & 13.3 & $72.3 *$ & 24.3 n.s. \\
Unamended control & 13.3 & 80 & 20.0 \\
Solarised for 7 weeks & 20.0 & $95.3 * *$ & 40.0 n.s. \\
Unsolarised control & 10.0 & 88.7 & 27.7 \\
\hline
\end{tabular}

$* P<0.05 ; * * P<0.01 ; * * * P<0.001 ;$ n.s., not significantly different. 


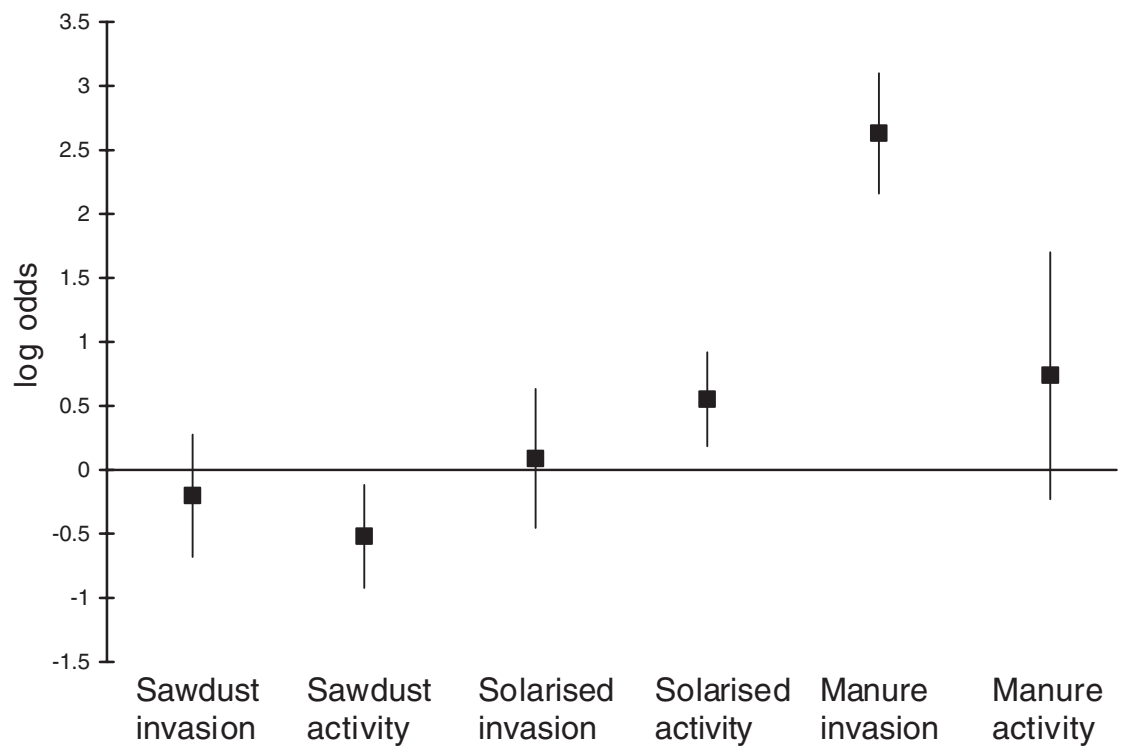

Fig. 1. Log of the odds ratio for the results of the analyses of deviance of the Foc activity and Foc invasion bioassays. Grande Naine plantlets were transplanted at 4 weeks post-deflasking into soil amended with composted sawdust or aged chicken manure, or soil solarised for 7 weeks. Results for each treatment were compared with an unamended, untreated control naturally infested with race 4 of the pathogen. Closed squares indicate the log of the odds ratio and vertical lines indicate the $95 \%$ confidence interval for the estimates. Vertical lines intercepting the zero base-line are not significantly different from the control.

189 root tips plated, indicating that the low recovery in the solarised treatment was not the result of saprophytic suppression of Foc during plate incubation. All of the pure cultures of FOC recovered from both the solarised and unsolarised treatments were volatile odour producers, consistent with the original culture used to pre-inoculate the root pieces (VCG 0120). As expected, all pure cultures tested for their vegetative compatibility grouping conformed to VCG 0120. Similarly, all of the pure cultures isolated from the composted and chicken manure amended soils and the controls were all volatile odour producers. No saprophytic strains of Fo were detected in either the soil or the amendments used.

\section{Effect of organic amendments and solarisation on symptom expression and Foc invasiveness}

As with the activity bioassays, Foc invasiveness was not affected by differences between waterbaths or between the 3 trays used for each series of experiments. Across all 3 experimental series, disease symptom expression in the unamended controls was uniformly low, ranging from 10.0 to $16.7 \%$ (Table 1). This was reflected in the uniform invasion scores, which varied from 20 to $27 \%$. As expected, amending the soil with chicken manure enhanced disease symptom expression (100\% of plantlets with symptoms). This was reflected in a very high Foc invasion score of $78.7 \%$, (significant at the 0.001 level, $\chi^{2}=152.631, P=0.0001$ ).
However, there was no evidence of disease suppression in either the composted sawdust or the solarised soil treatments. On the contrary, there was evidence of a marginal increase in symptom expression in the solarised soil, from 10 to $20 \%$. This was reflected in the invasiveness of Foc, with $27.7 \%$ of plantlets invaded in the control and $40 \%$ in the solarised soil. However these results were not statistically significantly different $\left(\chi^{2}=0.102, P=0.750\right.$ for solarisation; $\chi^{2}=0.683$, $P=0.409$ for sawdust). All of the pure cultures isolated from the banana plantlets from both amended and unamended soils were volatile odour producers (VCG 0120). There was no evidence of the presence of saprophytic strains of $F o$ nor of any other pathogenic strains in any of the isolates recovered from the transplanted banana pseudostems.

The lack of association between the Foc activity and invasion bioassay results across the 3 series of experiments becomes most evident when the log of the odds ratios are compared (Fig. 1). If an increase in the activity of the pathogen were causally related to the frequency of invasion, then the rate of change in one should be reflected in the other. On the contrary, where the activity in soil amended with sawdust is suppressed relative to the control, invasion of the pseudostems is not. Where Foc activity in the solarised treatment is enhanced, invasion is not. And where the invasion of pseudostems is substantially enhanced, as in the case of the chicken manure treatment, activity is not. 
Table 2. Nitrogen content of soil naturally infested with Foc race 4 , either solarised for 7 weeks or amended with $10 \%$ aged chicken manure or $20 \%$ composted sawdust

Soil samples were taken from the trays after 4 weeks, at the completion of the bioassays. Values are the mean of 3 samples \pm standard deviation

\begin{tabular}{|c|c|c|c|}
\hline Soil treatment & $\begin{array}{c}\mathrm{NH}_{4} \\
(\mathrm{mg} / \mathrm{kg})\end{array}$ & $\begin{array}{c}\mathrm{NO}_{3} \\
(\mathrm{mg} / \mathrm{kg})\end{array}$ & $\begin{array}{c}\text { Total } N \\
(\% \text { by wt })\end{array}$ \\
\hline Unamended & $3.65 \pm 0.20$ & $116.74 \pm 0.93$ & $0.17 \pm 0.01$ \\
\hline $\begin{array}{l}\text { Amended with } 10 \% \\
\text { chicken manure }\end{array}$ & $413.04 \pm 4.32$ & $321.60 \pm 3.54$ & $0.31 \pm 0.00$ \\
\hline $\begin{array}{l}\text { Amended with } 20 \% \\
\text { sawdust }\end{array}$ & $64.93 \pm 2.06$ & $115.65 \pm 0.89$ & $0.20 \pm 0.00$ \\
\hline Solarised for 7 weeks & $11.67 \pm 0.54$ & $208.03 \pm 2.31$ & $0.20 \pm 0.00$ \\
\hline
\end{tabular}

\section{Effect of organic amendments and solarisation on nitrogen levels in the soil}

All treatments enhanced the total nitrogen content of the soil, when measured at the end of the 4-week bioassay (Table 2). As expected, the nitrogen content was greatest in the chicken manure amended soil, with a higher proportion of the $\mathrm{N}$ in the ammonium form. Despite the addition of urea to the compost, there was visual evidence of nitrogen immobilisation in the sawdust treatment. Plant leaf areas were smaller than in the unamended control, and the leaves were not as green. This is reflected in the differences between the mineral $\mathrm{N}$ and total $\mathrm{N}$ analyses, with a higher portion immobilised in the microbial biomass. The concentration of total $\mathrm{N}$ in the solarised soil was the same as in the sawdust treatment. However, in contrast, the effect of solarisation on the microbial population increased the availability of mineral $\mathrm{N}$, predominantly in the nitrate form.

These changes in nitrogen availability were associated with changes in Foc invasion, but not with Foc activity (Fig. 2). Foc invasion was greatest in the chicken manure treatment, as was the increase in mineral $\mathrm{N}$ (predominantly in the ammonium pool). Invasion was marginally greater, although not statistically significant in the solarised soil treatment, as was the increase in mineral $\mathrm{N}$ (predominantly in the nitrate form). Where there was a negligible difference in mineral $\mathrm{N}$, as with the sawdust treatment, neither the disease incidence nor the Foc invasion scores differed from the unamended control. Mineral nitrogen levels do not appear to be associated with changes in the activity of Foc in the soil.

\section{Discussion}

Studies on the effects of adding compost or other organic amendments to control wilt diseases implicate the role of antagonistic microbes in suppressing the pathogen population (Scher and Baker 1980; Greenberger et al. 1987; Pera and Calvert 1989; Serra-Wittling et al. 1996). For example, amending naturally infested soil with chitin can enhance the activity of actinomycetes, known antagonists of Fusarium pathogens (Maurer and Baker 1965). Ammonium is released during the decomposition of chitin, and has been shown to induce the lysis of Fusarium chlamydospores (Schippers and van Eck 1981; Loffler et al. 1986). Similarly, solarisation has rendered formerly conducive soils suppressive to wilt diseases (Katan 1981). Pathogenic

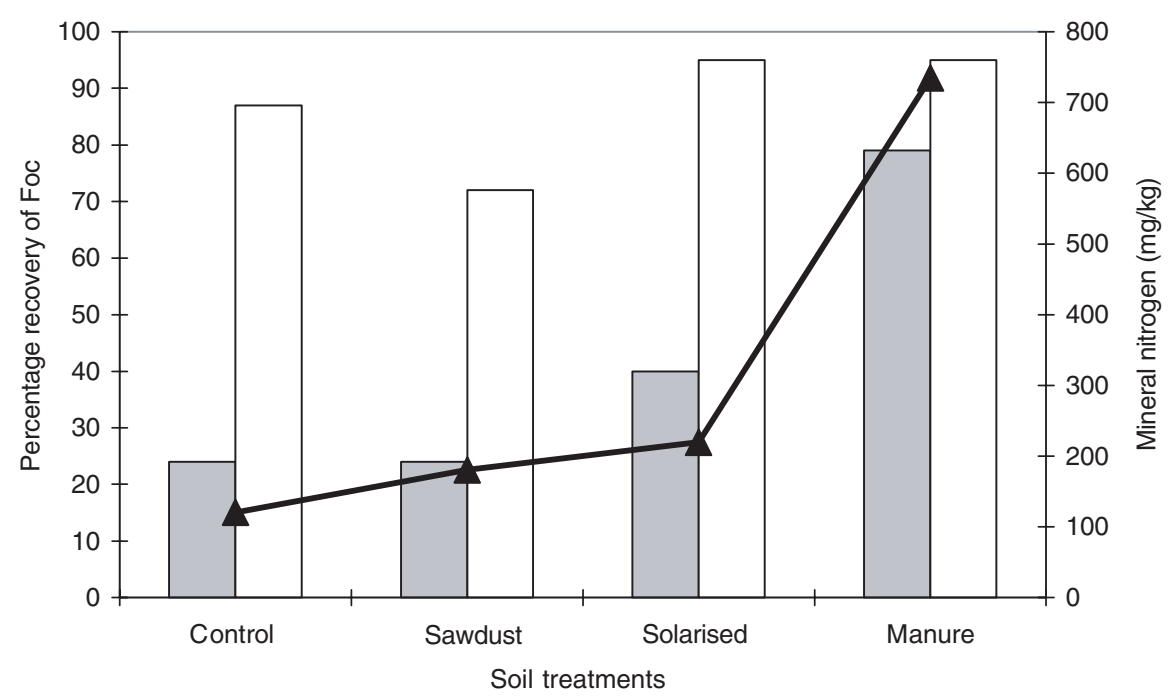

Fig. 2. Frequency of Grande Naine banana plantlets from which Foc was recovered from pseudostem tissue (invasion bioassay, grey bars), frequency of buried root segments from which FOC was recovered (activity bioassay, white bars), and the concentration of mineral nitrogen remaining in the soil at the completion of each bioassay (closed triangles connected by black line, $\mathrm{mg} / \mathrm{kg}$ ). Soil was amended with either composted sawdust or aged chicken manure, or was solarised for 7 weeks. Each treatment was compared with an unamended control, naturally infested with race 4 of the pathogen. 
activity is reduced not only by lethal heat (Arora and Pandey 1989), but also by the alteration of microbial populations in favour of antagonistic genera such as the actinomycetes (DeVay and Katan 1991). In the case of chickpeas, the induced suppression reduced the incidence of Fusarium wilt disease in 2 subsequent crops (Arora and Pandey 1989). The results presented here contradict these findings.

The addition of $10 \% \mathrm{v}: \mathrm{v}$ chicken manure was used as a reference to test the sensitivity of the activity and invasion bioassays. Relative to the chicken manure results, no other soil treatment significantly enhanced or suppressed the frequency of invasion of plantlet pseudostems by Foc (Fig. 1). Yet the activity of FOC in the soil was significantly reduced by the addition of composted sawdust, and unexpectedly, activity was enhanced in the solarised soil. Although statistically significant, changes in activity from 80 to $72 \%$ and from 89 to $95 \%$ in the unamended to the amended compost and solarised treatments may not be biologically significant. In many biological systems, the magnitude of the response elicited at higher doses of application of a substance can diminish. Accordingly, one could argue that the change in activity recorded in both the solarisation and compost treatments was insufficient to elicit a measurable response in the host. However, this logic is not supported by the results of the chicken manure treatment. The activity of Foc is of a similar order of magnitude ( $87 \%$ unamended, $95 \%$ amended; not significantly different), but the frequency of invasion was enhanced from 24 to $79 \%$ (significant at 0.001 ). This lack of association between the activity of Foc and the frequency of invasion supports the hypothesis that although infection by the pathogen is required for Panama disease, disease severity does not conform to a dose-response model. Factors predisposing the host to disease may determine disease severity, not changes in the activity of the pathogen (Pittaway et al. 1999). The possible role of nitrogen in determining the severity of Fusarium wilt disease has been reported in the literature (Rishbeth 1957; Maurer and Baker 1965; Huber and Watson 1974).

Nitrogen is considered second only to potassium in terms of its importance in banana growth and production (Lahav 1995). Under conditions of deficiency, nitrogen is strongly redistributed from the older to the younger leaves. Bananas cannot store nitrogen, other than by using it for growth. The growth stimulation associated with applications of sulfate of ammonia (Simmonds 1960) suggests that bananas are better adapted for ammonium rather than nitrate utilisation. In the current study, increases in the mineral nitrogen content of the soil treatments were associated with increases in the frequency of invasion (Fig. 2). However, when urea was added to soil naturally infested with race 1 at a rate equivalent to the addition of $10 \% \mathrm{v}: \mathrm{v}$ chicken manure, no disease enhancement was observed (N. Nasir et al. unpublished data).

Some critics attribute the increase in disease severity associated with amending naturally infested soil with chicken manure to ammonium toxicity. However, the symptoms observed across all 3 treatments and the respective controls were similar. There was also no evidence of ammonium leaf tip burn or reduced emergence (Sims and Wolf 1994; Riegel and Noe 2000) in weed seedlings germinating in the soil amended with chicken manure within the 2-week equilibration period. The chicken manure used in this study had been stockpiled for over 6 months, during which time up to $48 \%$ of the total $\mathrm{N}$ and $70 \%$ of the $\mathrm{NH}_{4}-\mathrm{N}$ could have volatilised as $\mathrm{NH}_{3}$ gas (Mahimairaja et al. 1994). Moreover, once incorporated into well-watered soil, ammonium is converted by microorganisms to either organic or nitrate nitrogen within 7-10 days (Mahimairaja et al. 1994; O’Brien and Barker 1996). On this evidence, it is highly unlikely that the increase in disease incidence recorded in the soil amended with chicken manure was due to ammonium toxicity.

Alternatively, the vegetative growth stimulation associated with applications of ammonium to bananas may have reduced the levels of circulating sugars and available nutrients, reducing the potential of susceptible plants to mobilise an effective defense response. Plant defense commonly involves the physical and chemical isolation of the pathogen within infected tissue, inducing a greater demand for metabolic substrates (Hutcheson and Buchanan 1983). The critical concentrations of nutrients required for growth are known to differ within the banana germplasm (Lahav 1995). Triploid and tetraploid bananas are the result of the natural hybridisation of Musa acuminata (A genome) and $M$. balbisiana (B genome). The $\mathrm{B}$ genome is considered to reduce the threshold concentration of nutrients required, whilst the AAA genome requires higher levels. Similarly, within the AAA genome the expression of nutrient deficiency symptoms differs significantly between cultivars. These results have implications for the field management of Panama disease, and for the development of screening techniques for the selection of cultivars with improved disease resistance. As the results presented in this paper suggest, strategies that reduce the activity of Foc in naturally infested soil are unlikely to influence the severity of Panama disease. The management of plant nutrition and genotypic selection is more likely to be effective. As a result of this study, banana growers in Indonesia have been warned of the dangers of using amendments such as uncomposted chicken manure as a fertiliser, and the chicken manure assay is being used to compare the resistance of local banana genotypes to different strains of the pathogen.

\section{Acknowledgments}

We gratefully acknowledge the cooperation of Dr Mike Smith and Ms Sharon Hamill in providing the tissue-cultured banana plantlets for this study. We also thank Dr Natalie Moore for providing the reference testers for the determination of the vegetative compatibility groupings, and 
for instructing us in the technique. Advice and discussions with Dr Allan Lisle on the statistical analysis of the data were invaluable.

\section{References}

Abawi GS, Lorbeer JW (1971) Populations of Fusarium oxysporum f. sp. cepae in organic soils in New York. Phytopathology 61, 1042-1048.

Amir H, Allabouvette C (1993) Involvement of soil abiotic factors in the mechanisms of soil suppressiveness to Fusarium wilts. Soil Biology and Biochemistry 25, 157-164.

Anon. (1989) 'Australian standard for potting mixes AS 3743.' (Standards Australia: Homebush, NSW)

Arora DK, Pandey AK (1989) Effects of solarization on Fusarium wilt of chickpea. Journal of Phytopathology 124, 13-22.

Baayen RP, Elgersma DM (1985) Colonization and histopathology of susceptible and resistant carnation cultivars infected with Fusarium oxysporum f. sp. dianthi. Netherlands Journal of Plant Pathology 91, 119-135.

Beckman CH, Halmos S, Mace ME (1962) The interaction of host, pathogen and soil temperature in relation to susceptibility to Fusarium wilt of bananas. Phytopathology 52, 134-140.

Catchpole V, Weier K (1980) Water pretreatment helps during extraction of mineral $\mathrm{N}$ from a clay soil. Communications in Soil Science and Plant Analysis 11, 327-333.

Dalal RT, Sahrawat K, Myers R (1984) Inclusion of nitrate and nitrite in the Kjeldahl nitrogen determination of soils and plant material using sodium thiosulphate. Communications in Soil Science and Plant Analysis 15, 1453-1461.

DeVay JE, Katan J (1991) Mechanisms of pathogen control in solarized soils. In 'Soil solarization'. (Eds J Katan, JE DeVay) pp. 87-101. (CRC Press: Boca Raton, FL)

Duff JD, Barnaart A (1992) Solarisation controls soilborne fungal pathogens in nursery potting mixes. Australasian Plant Pathology 21, 20-23.

Greenberger A, Yogev A, Katan J (1987) Induced suppressiveness in solarised soil. Phytopathology 77, 1663-1667.

Hoitink HAJ, Fahy PC (1986) Basis for the control of soilborne plant pathogens with composts. Annual Review of Phytopathology 24, 93-114.

Huber DM, Watson RD (1974) Nitrogen form and plant disease. Annual Review of Phytopathology 12, 139-165.

Hutcheson SW, Buchanan RB (1983) Bioenergetic and metabolic disturbances in diseased plants. In 'Biochemical plant pathology'. (Ed. JA Callow) pp. 327-345. (John Wiley and Sons: Chichester, UK)

Kai H, Ueda T, Sakaguchi M (1990) Antimicrobial activity of bark compost extracts. Soil Biology and Biochemistry 22, 983-986.

Katan J (1981) Solar heating (solarization) of soil for control of soilborne pests. Annual Review of Phytopathology 19, 211-236.

Lahav E (1995) Banana nutrition. In 'Bananas and plantains'. (Ed. S Gowen) pp. 258-316. (Chapman and Hall: Suffolk, London)

Loffler HJ, Cohen EB, Oolbekkink GT, Schippers B (1986) Nitrite as a factor in the decline of Fusarium oxysporum f. sp. dianthi in soil supplemented with urea or ammonium. Netherlands Journal of Plant Pathology 92, 153-162.
Mahimairaja NS, Bolan NS, Hedley MJ, Macgregor AN (1994) Losses and transformation of nitrogen during composting of poultry manure with different amendments: an incubation experiment. Bioresource Technology 47, 265-273.

Maurer CL, Baker R (1965) Ecology of plant pathogens in soil. 1. Influence of glucose, cellulose and inorganic nitrogen amendments on the development of bean root rot. Phytopathology 55, 69-72.

Moore NY, Hargreaves P, Pegg KG, Irwin JAG (1991) Characterisation of strains of Fusarium oxysporum $\mathrm{f}$. sp. cubense by production of volatiles. Australian Journal of Botany 39, 161-166.

Moore NY, Pegg KG, Allen RN, Irwin JAG (1993) Vegetative compatibility and distribution of Fusarium oxysporum f. sp. cubense in Australia. Australian Journal of Experimental Agriculture 33, 792-802.

O'Brien TA, Barker AV (1996) Evaluation of ammonium and soluble salts on grass sod production in compost. II Delaying seeding after compost application. Communications in Soil Science and Plant Analysis 27, 77-85.

Oritsejafor JJ, Adeniji MO (1990) Influence of host and non-host rhizospheres and organic amendments on survival of Fusarium oxysporum f. sp. elaeidis. Mycological Research 94, 57-63.

Pegg KG, Moore NY, Bentley S (1996) Fusarium wilt of bananas in Australia: a review. Australian Journal of Agricultural Research 47, 637-650.

Pera J, Calvert C (1989) Suppression of Fusarium wilt of carnations in composted pine bark and a composted olive pumice. Plant Disease 37, 699-700.

Pittaway PA, Nasir N, Pegg KG (1999) Soil receptivity and host-pathogen dynamics in soils naturally infested with Fusarium oxysporum f. sp. cubense, the cause of Panama disease. Australian Journal of Agricultural Research 50, 623-628.

Porter IJ, Merriman PR (1985) Evaluation of soil solarisation for control of root diseases of row crops in Victoria. Plant Pathology 34, 108-118

Riegel C, Noe JP (2000) Chicken litter soil amendment effects on soilborne microbes and Meloidogyne incognita on cotton. Plant Disease 84, 1275-1281.

Rishbeth J (1957) Fusarium wilt of bananas in Jamaica. 11. Some aspects of host-parasite relationships. Annals of Botany 21, $215-245$.

Serra-Wittling C, Houot S, Alabouvette C (1996) Increased suppressiveness to Fusarium wilt of flax after addition of municipal solid waste compost. Soil Biology and Biochemistry 28, 1207-1214.

Scher FM, Baker R (1980) Mechanisms of biological control in a Fusarium-suppressive soil. Phytopathology 70, 412-417.

Schippers B, van Eck WH (1981) Formation and survival of chlamydospores in Fusarium. In 'Fusarium: diseases, biology and taxonomy’. (Eds PE Nelson, TA Toussoun, RJ Cook) pp. 250-260. (Pennsylvania University Press: USA)

Simmonds NW (1960) 'Bananas.' (Longmans: Bristol, Great Britain)

Sims JT, Wolf DC (1994) Poultry waste management: agricultural and environmental issues. Advances in Agronomy 52, 1-83.

Manuscript received 25 July 2000, accepted 20 December 2002 